\title{
A critical study on female roles in television commercials of Bangladesh
}

\author{
Moriom Begum Mim
}

Department of Mass Communication and Journalism, Bangladesh University of Professionals (BUP), Mirpur Cantonment, Dhaka 1216, Bangladesh

Email: mail2moriommim@gmail.com

\section{Maliha Tabassum}

Department of Mass Communication and Journalism, Bangladesh University of Professionals (BUP), Mirpur Cantonment, Dhaka 1216, Bangladesh

Email: maliha.tabassum@bup.edu.bd

\begin{abstract}
Media representation of female gender roles in advertising are relentlessly contested themes in a traditional society. Stereotypical representation not only limits the socially accepted traditional roles of gender, but also has an impact on how people perceive women. This study has focused on how women characters are constructed in order to understand reflection of stereotypical gender norms in Bangladeshi television commercials. Stuart Hall's representation theory has adapted as the framework for conceptualizing the context of this study and scrutinizing the data. Following both qualitative and quantitative methods, this paper has explored how representations constitute unequal gender identities, traditional norms and perpetuate subtle forms of colorism towards women. This study found that dominant patriarchal ideology is deeply embedded in television commercials of Bangladesh; there is a discrimination towards the construction of women's image. Moreover, such media representations generate the ideology of beauty in a negative way and push the concept of colorism towards women.
\end{abstract}

Keywords: Female Role, Television Commercials, Bangladesh, Representation, Gender. 


\section{INTRODUCTION}

Cooking and taking care of children are considered as primary responsibilities of women. But in recent times, Bangladesh has gained significant progress in the field of women's empowerment (Haque, 2019). Moreover, a large number of women are taking part in economic activities and contributing to the wellbeing of their family. Bangladesh has started to believe that active participation of women in the economic sector will be a major driving force to attain middle-income status (Hamid, 2019).

It is often said that advertisements mirror a society. Studies on representation of gender in advertisements have drawn attention of researchers and scholars over the past few decades. Advertisers are most often criticized for representing stereotypical gender norms, especially for the conventional representation of women.

Previous studies on Bangladeshi advertisements have shown that women are represented as soft, gentle, emotional, attractive and charming whereas men are portrayed as masculine-hard, tough and macho (Khan, 2019). Moreover, such commercials depict females as the obsessive domestic selfless nurturer of their families, on the contrary male are conventionally shown as saviors (Pia, 2018). The typical stereotypical gender bias still exists in the advertisements of Bangladesh that uphold the ideology that a female's place is in the kitchen (Jui, 2019).

Furthermore, advertisements portray women in limited roles as they never seem to be shown in business roles, work settings or any position involving authority (Asemah, Edegoh \& Ojih, 2013). They are conventionally confined to household chores, mother or caretaker roles whose world centers around the house whereas men are represented as strong and independent (Nagi, 2014). This sort of representation encourages women to believe that they are ought to be weak, mindless and needy. It also has an impact on the attitude of men to perceive that women are mere sex objects (Gulati, 2014). So, it can be argued stereotypical gender-role representation in television commercials have a deep influence on any society. Such portrayals only reinforce the stereotypical gender norms, values and discrimination between men and women. This sort of gender differentiation is then accepted as norms and values in society.

Advertisements represent femininity with beauty and perfection but, women cannot achieve this unrealistic standard of perfection, as a consequence the feeling of inadequacy and dissatisfaction is conventional today (Krawczyk 
\& Thompson, 2015). Fairness-based advertisements make skin color-based discrimination in the society. Generally, people are misled into buying such products due to the impact of mass advertisements (Gupta, 2021). In reference to this study, colorism is defined as the practice of favoring lighter skin over darker skin (Grant, 2020).

Due to the significance of the societal impact for such representation, there are several reasons why gender in advertising is considered as the most contested area of mass media. This sort of stereotypical projection of women's images deny the comprehensive framing of women's contribution in economics, society, and culture. This is not a question of fixed narratives that shortens an image of a modern career centric independent woman into a picture of a woman performing traditional household tasks, but the underlying ideology that solidifies such a fragile image of a woman in the mind of mass audiences. The recent advancement and evolution of women's existence and participation in social, economic, and political context have given rise to questions regarding the relevant portrayal of women in advertisement.

In this 21th century, advertisements are still restricted and questioned to reflect the image of modern women in Bangladesh. This study is significant because advertisements of Bangladesh predominantly have treated one gender superior over another which can perpetuate dominant sexist ideology in the society. Taking the deep social impact of advertisements into consideration, the purpose of this study is to explore the cultural politics of gender in the persuasive narratives of television commercials in Bangladesh. The first phase of this study has examined what sort of the roles are conventionally assigned for women. The second phase has scrutinized whether images of women generate stereotypical norms or they are treated as subordinate to men. This part has also investigated how the ideology of colorism is imposed on women. It should be noted this study considers female role as the main job or social status of woman character in advertisements.

\section{LITERATURE REVIEW}

\section{Previous studies}

This study derived inspiration from previous academic studies. Holtzhausen, Jordaan \& Norths (2011) explored women role portrayals in South African television commercials. Following content analysis, they found 
that stereotypical roles of domesticated or overly sexualized characters were not widespread in advertisements. According to them, South African advertisers preferred to emphasize on women's social image rather than her professional image. But women were also represented in multiple roles in a single commercial that showed the upgraded lifestyle of the modern South African woman. However, advertisers linked women to consumer decision making for low-involvement products instead of high-involvement products.

Huang \& Lowry (2012) focused on gender, racial and brand differences in 19 Chinese consumer magazines from a stratified random sample. Using content analysis, they attempted to give a comparative overview of nudity between Chinese and western models in magazine advertising. They found that female models were more likely to be represented in different levels of nudity than male models, while western models were more likely to be shown in different levels of nudity than Chinese models. They suggested that sexism in advertising is a cross-cultural phenomenon and western advertising models were the trend setters of sexual images in Chinese magazine advertising.

Kumar (2017) attempted to explore women's role in sexually appealing ads from the 1990's till 2017 and perception of consumers towards these ads. This study conducted qualitative method techniques such as literature review and analyzed the content of ads. This study scrutinized the difference in perception of advertisements among generations and explored the intentional shift of focus in brands from the features to the models in the ads of India. This research argued that women became victim in the advertisements as well as sex appeals has used to attract consumers. Furthermore, the use of such themes builds a negative impression about the brand in the consumer's mind.

Asemah et al. (2013) investigated the attitudes of the audience towards representation of women in television commercials. They applied both Constructivism theory and Standpoint theory as a theoretical framework to explore the result. Employing a survey method, this study found that female respondents were not satisfied with the way they were represented in television commercials. This research recommended that female models should be depicted in the positive light while advertising products.

Few kinds of literature focused on women's portrayal in television advertisements of Bangladesh. Nahar (2019) attempted to explore whether women representation in Bangladeshi advertisements has changed with the context of time and reasons behind the changes. Employing a qualitative method, 40 advertisements and 8 in-depth interviews were taken as sample 
size. Using thematic analysis and Barthian Sociological approach, the result found that the pattern of women representation has changed slowly. This study recommended that the ad agencies should alter the scenario of women portrayals in advertisements. Khan (2019) investigated gender representation in print advertisements of Bangladesh. Following both content analysis and discourse analysis, this research found that advertisements in print newspapers were male dominated. Moreover, men were depicted as sports persons, doctors, engineers whereas women were portrayed as mothers and homemakers in most of the advertisements. Rosul (2011) scrutinized how fairness-product advertisements manipulate target audiences and the impact of their message. This research gathered data from advertisements and interviews which were analyzed in terms of discourse, ideology and power. Result showed that skin whitening advertisements of Bangladesh portrayed that fair skin help to achieve the ideal face, partner, success and attention from the opposite sex.

Reviewing the existing literature, it has found that the majority of the studies focused on how gender has been portrayed in advertisements by using a qualitative method of content analysis. In Prior studies of Bangladesh, researchers have taken a small sample of television advertisements to examine stereotypical representation of gender. They neither applied quantitative method nor scrutinized how the ideology of colorism is imposed on women in Bangladeshi advertisements. In addition, there is a gap for research considering a large sample of prime-time television advertisements. Taking this research gap into consideration, this paper has employed both qualitative and quantitative methods to explore the quantity of assigned roles, voice overs, central characters, product authorities, ideology of colorism and how women images are constructed in prime-time television commercials. Thus, the present research is distinctive in the socio-cultural context of Bangladesh. Since stereotypical gender portrayal in advertisements is quite influential to perpetuate gender inequality and dominant sexist ideology in the society; hopefully this study will add great value in the field of academic research by making practitioners aware to construct positive portrayal of women in commercials of Bangladesh. In addition, it can be an important contribution for future research regarding the relevance of female roles in television advertisements.

\section{Theoretical framework}

After discussing the earlier studies, it appears that Representation theory is quite relevant with this study. The selected advertisements have been analyzed 
in the light of the theoretical concept of Stuart Hall's Representation Theory. This theory is pertinent to this study as it has facilitated understanding of how a particular group of people is constructed in different contexts. Hall (1997) asserted scholars investigate the concept of representation within this culturalcritical paradigm of media studies and his idea suggests not to decode media images as simple reflection or reality. Representations are embedded in a saturated media stream and construct norms and common sense about people, groups, and institutions in contemporary society. He illustrated representations are constructed to appear natural. His assumption for the analysis of representation is the post structural principle that meaning can never be finally fixed.

Representation theory requires interpretation to make a logical argument for a particular event or group of people that is shown through the media. Employing Hall's representation theory as a theoretical framework, this paper has examined what is being represented and how in advertisements. Whether any significant issue is absent or is there any characteristic excluded in this representation. Furthermore, this study has interpreted the content of advertisements with Hall's representation theory in order to understand hidden messages.

\section{METHODS}

Advertisements representing women aired on television channels such as NTV, Somoy tv and Channel i were included in the sample size. These channels were chosen because of viewership among the audience. According to research, NTV, Somoy tv, Channel i have got 1st, 2nd and 3rd position respectively based on the most watched Bangladeshi television channels (Islam, 2018). This study has examined a sample of prime-time television advertisements appearing in the 7PM to 9PM (2 hours) from 1 May to 10 May 2021, a total of 10 days. All repeat commercials have been excluded because this study intended to examine woman portrayal in each advertisement. Finally, a total of 130 television commercials were available as a purposive sample to analyze.

By considering the needs and objectives of this study, both qualitative and quantitative methods have been used to explore the cultural politics of gender in the persuasive narratives of television commercials in Bangladesh. A total of 130 contemporary television commercials have been chosen purposely to explore the female roles in advertisements. Data is carefully collected and displayed in the form of the graph charts to show the percentages. Again, from 
the top 3 categories of bar graph regarding female roles, seven (7) advertisements have been selected to conduct the content analysis.

The first portion of this research has conducted quantitative content analysis in order to procure numerical data on assigned roles, voice overs, central characters and product authorities in advertisements. The second portion has conducted qualitative content analysis to explore the construction of women's image and the ideology of colorism in television commercials. In reference to this study, quantitative research deals with numerical data to generalize results to wider populations. On the contrary, qualitative research is the process of interpreting non-numerical data that seeks to understand how an individual subjectively perceives meaning to their social reality (McLeod, 2019).

\section{RESULTS AND DISCUSSION}

\section{First Phase: Quantitative analysis}

A central female figure has been selected from each advertisement; therefore 130 main characters have come out from 130 television commercials. While procuring key figures from the selected television commercials, it is encountered that multiple characters exhibit properties of a central character or have characteristics equivalent to a central figure. However, to address this dilemma certain parameters have been put into the filtering process. The parameters follow as the character must be of a female gender and she must play a prominent role. Thus, a total of 130 central figures were analyzed to identify women's roles in Bangladeshi tv commercials. Then women's roles are identified based on the character's appearance, focus and actions. Furthermore, the props, the settings (indoor or outdoor) are also observed carefully to determine a woman's role in the commercial.

This study classifies specific role categories like housewife, spouse, mother, beauty conscious woman, career centered woman, or fall into the statistical category under other labels. The figure 1 illustrates the constancy of the representation in contemporary television commercials. 


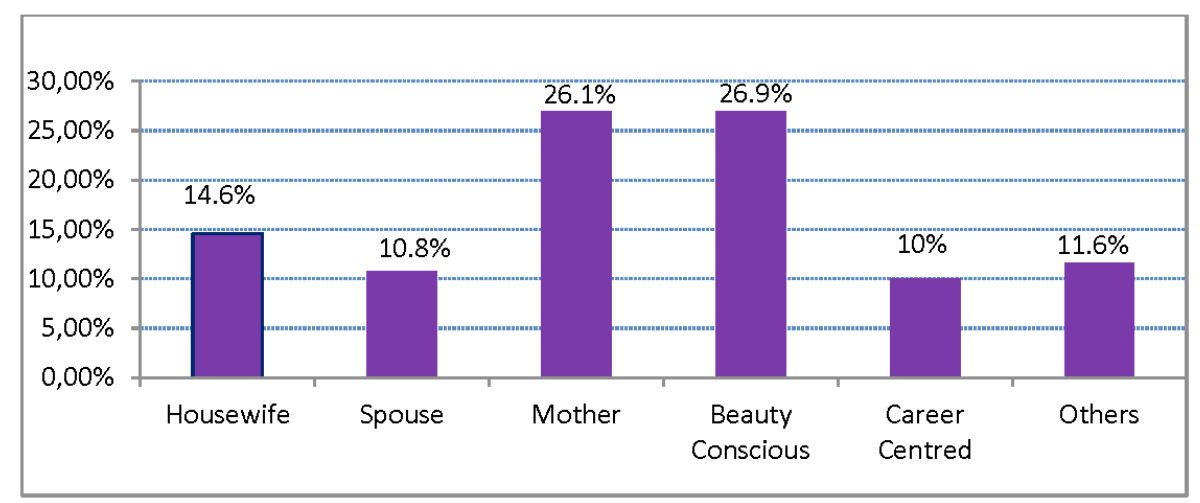

Figure 1: Categories of female roles in television commercials.

Figure 1 implies that females are mostly assigned in the role of a beauty conscious. It is the most prevalent female character role in Bangladeshi television commercials, with the major percentage $(26.9 \%)$. Then the role of mother secures the second most prevalent with percentage of $(26.1 \%)$. The role of a housewife holds the third position with a percentage of $(14.1 \%)$. The role of the other category secures fourth position (11.6\%) and spouse character gets fifth position $(10.8 \%)$. The role that is projected the least often was the career centered (10\%).

However, the category of others does not align with specified categories. Women with miscellaneous roles are labelled under the other category. For example, a cheerful young lady is pictured hanging out with friends and cannot be classified within impactful character roles. That is why it is quite difficult to align them with a particular social role. Thereafter, this sort of roles are labelled within one category of others.

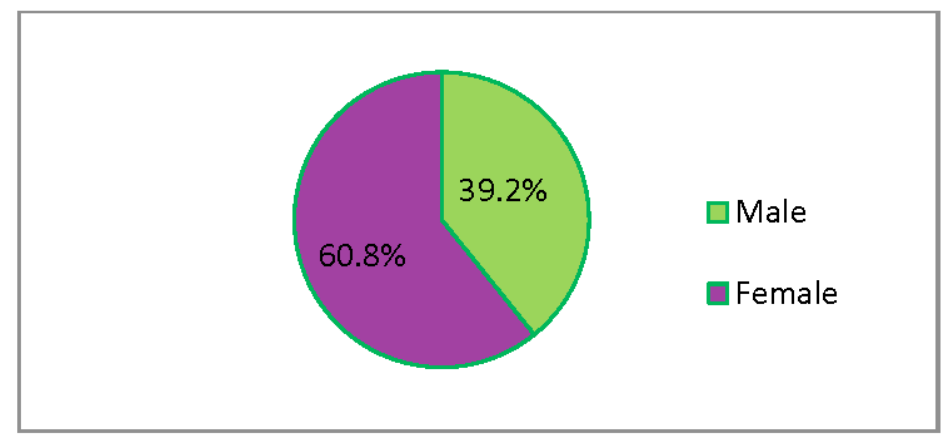

Figure 2: Frequency of voice over in television commercials 
Figure 2 points out the frequency of voice over in this study. Very surprisingly female voice overs are more apparent than male voice overs in terms of product authority. Female voice overs constitute $60.8 \%$ of advertisements whereas male voice overs capture only $39.2 \%$ of the television commercials.

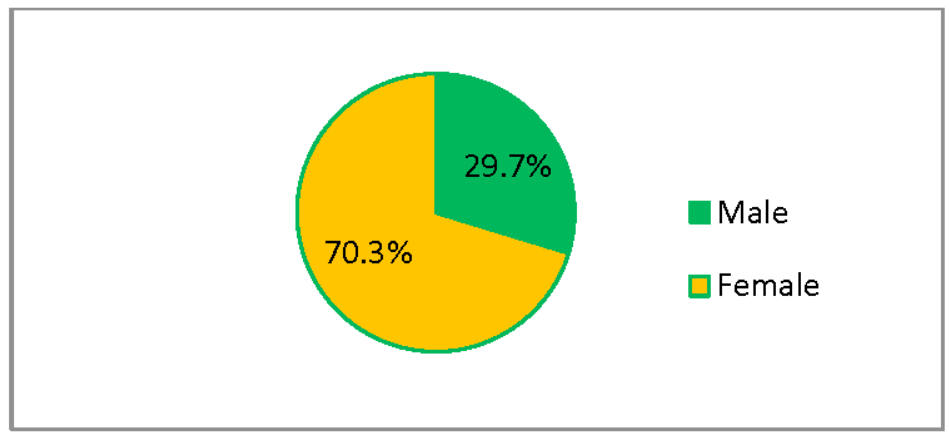

Figure 3: Central character in advertisements.

Figure 3 points out $29.7 \%$ of central figures in television commercials are men, while $70.3 \%$ are women. It indicates that female models get more importance as central character in television advertisements of Bangladesh.

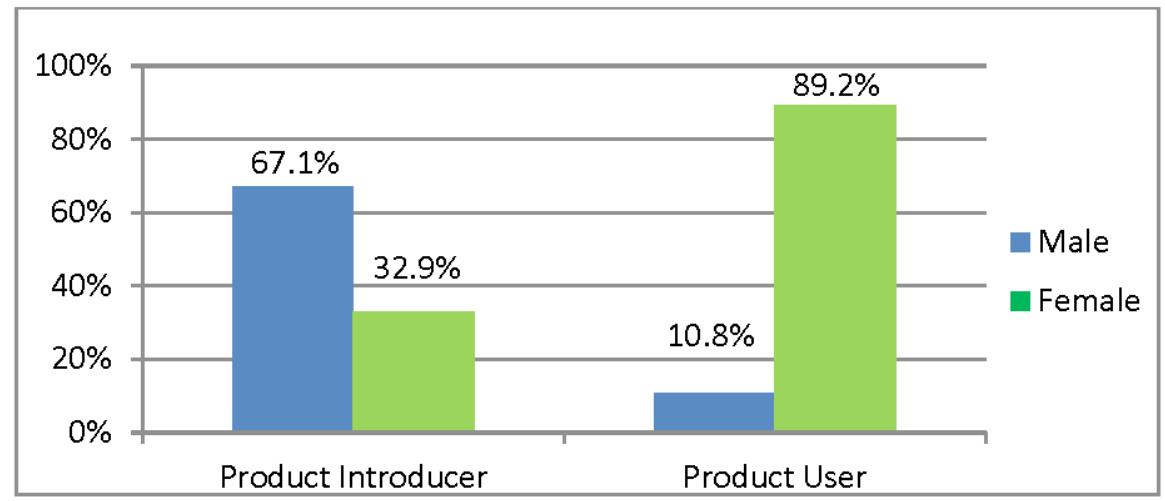

Figure 4: Product authority in television commercials.

Figure 4 shows $67.1 \%$ of men are represented as product introducer, while $32.9 \%$ of women are featured as product introducer in terms of product authority. On the contrary, $10.8 \%$ of men are portrayed as product user while $89.2 \%$ of women are represented as product user. It indicates that male models are shown as more knowledgeable and expert than female models to give scientific arguments regarding the product. 


\section{Second Phase: Qualitative analysis}

Among the top 3 subcategories of women roles in advertisements (Figure 1), seven advertisements have been selected to conduct qualitative content analysis to understand how women's images are constructed. This study has divided selected three advertisements into three categories based on the content.

Table 1: Advertisement's categories based on female roles.

\begin{tabular}{ccc}
\hline S1. & Role & Product \\
\hline 1. & Beauty conscious & Fairness cream, soap, body lotion. \\
\hline 2. & Mother & Water filter, baby diaper. \\
\hline 3. & Housewife & Detergent powder, cooking spices. \\
\hline
\end{tabular}

With the help of quantitative analysis, this study found some issues of concern relating to the television commercials which have been analyzed below.

a. Topic of concern: Fair \& Lovely Fairness Cream Advanced Multivitamin (HD glow skin)

Celebrity Yami Gautam as a presenter informs the audience that the new Fair \& Lovely will not promote brightness. The female audiences react shockingly. One of them asks why? Then the presenter replies that the new Fair \& Lovely will promote HD glow. She points to a screen where a demonstration appears narrating how Fair \& Lovely nourishes inside the skin and erases the dark cell and radiances HD glow. The female audience are deeply concerned about beauty as if the goal of their life is to look beautiful consuming Fair \& Lovely. Alluring graphics are used to emphasize how the cream has the great power to make skin fair. A tough male voice attempts to assure and convince the female audiences to trust and purchase Fair \& Lovely for glowing skin. However, this is a foreign TVC that has dubbed in Bangla, but Unilever doesn't bother to make a new one to broadcast in Bangladesh.

b. Topic of concern: LUX Beauty Is Our Right (Soft and beautiful skin)

Celebrity Bidya Sinha Saha Mim says that people will criticize your appearance, but beauty is our right. Beginning day with LUX gives her a soft skin and perfume lasts for a long time. It has portrayed the female model 
in a seductive way who takes her bath in a bathtub. This advertisement emphasizes the beauty of a woman. But how can beauty be the right of women? It does not mention clearly what are the measurements of beauty or what categories are needed to be a beautiful human being. Although a female is represented as the main character, it perpetuates stereotypical norms that beauty is required for women more than men. It brings the message; a female can be a desirable one by using Lux beauty soap. Moreover, she is dressed up as a sexy woman by objectifying herself that also symbolizes how an ideal beautiful woman should look like. It represents the message that a perfect woman has to be beautiful and glamorous, so they need to take care of appearance.

\section{c. Topic of concern: Vaseline Healthy White (Body Brightness)}

A female photographer is shown who takes pictures on a seashore on a hot sunny day. Her skin loses beauty in extreme sunlight and becomes dry in winter. Then comes Vaseline Healthy White on the screen, consumption of the product will result in repair skin damage and restore fairness. A graphic illustration has been given on how nutrition is absorbed inside any damaged skin. Bubble shaped nutrition rejuvenates skin. A female voice over narrates "Nothing can stop her from moving forward. This is the healing power of Vaseline". This ad represents a career-oriented woman, but dark and dry skin is the biggest obstacle in the pursuit of success. But nothing can bring her down as she will be using the Vaseline Healthy White. Consuming the fairness lotion, she can relive her fairness. In this regard, questions may arise how ad agencies consider dark skin as a hindrance in women's life.

\section{d. Topic Of Concern: Pureit Classic (Water Purifier)}

Celebrity Chanchar Chowdhury goes to a house in disguise and knocks at the door. A woman comes from the house with her son, then the man asks for drinking water. While she gives a glass of water, he asks whether the water is boiled or not. The woman replies "Yes, of course"! Then he discloses his identity and introduces her with Pureit Classic that removes viruses, bacteria, and pollution of the modern era. In this TVC, a male character appears to inform a housewife how to ensure proper purification for water. It projects a woman completely unaware of the effects of harmful invisible metals contaminated in water; and needs men's advice in understanding health issues regarding that, finally discovering a product and getting the solution. The tough male voice motivates the 
audience to trust that this product is useful for water purification. The man is represented as a powerful influencer or instructor; on the contrary the woman follows his advice, placing as subordinate to the man. The message emphasizes that women can not think rationally without the help of man.

e. Topic of concern: Supermom Baby Diaper (Take care of baby)

The name of the product Supermom Baby Diaper itself is a gender insensitive word that suggests a meaning that the image of a diaper is associated with mothers and their babies. This implies the exclusive duty of a mother is to raise children that reinforces stereotypical gender roles. For this reason, the mother has left the job, although her husband tells not to leave it. He assures her to share some responsibility for their baby and introduces with Supermom Baby Diaper. With the support of husband, she can progress her career using Supermom Baby Diaper for her infant. Then a voice narrates that anyone can take responsibilities of babies with the help of this baby diaper. It generates a stereotypical message that fathers can not take care of newborn baby, but he can handle this problem by using this product. Since male character introduces the woman with the Supermom Baby Diaper, the man is represented as a powerful instructor, whereas the woman follows his advice.

f. Topic of concern: Fast Wash Detergent Powder (To remove dirt from the cloth)

In this TVC, celebrity Nushrat Fariha and her husband are shown to get ready to surprise each other on their first marriage anniversary. Meanwhile, they clash with each other; as a result, the cake spoils their dress. While the husband asks, "What will I do now?", she appears with Fast Wash Detergent Powder. She says that it will remove all the spots from the cloth and the color guard will help to protect the color as a new cloth. Nushrat Fariha successfully washes her husband's dirty cloth and relieves him from tension. It also shows that clean clothes make their bonding strong. Therefore, it brings a message that an ideal wife has to absorb the skill of washing clothes.

\section{g. Topic of concern: Radhuni Basic Spice (Pure Cooking spices)}

In this TVC, the traditional role of a housewife is shown. She performs household chores carefully and inspects her child's study habit. She meticulously examines fish sizes and loves to cut vegetables accurately. A male voice endorses her orthodox household activities and narrates that 
Raduni maintains the quality in producing goods in the same manner she performs household duties. The advertisement inspires the woman as a homemaker that reinforces the traditional role of women. The hidden message conveys that a good female should do all the domestic work in the house. She also has to absorb the caliber of cooking delicious foods. It represents an image of a traditional housewife whose main duty is limited inside the home.

\section{Key findings and discussion}

\section{a. Social roles of women in advertisements}

The category of beauty conscious woman tops with $26.9 \%$, then the category of mother occupies the second position with $26.1 \%$ and finally with the category of housewife secures the third position with $14.6 \%$. In the light of the findings, it can be argued that women are featured and represented in less significant roles in the television commercials of Bangladesh. But, roles of traditional women are not unprecedented; quite a few television commercials portray women as career centered that indicate some advertisers attempt to manifest the image of the modern and individual Bangladeshi women. It should be noted that a large portion of advertisements feature women as worrying about skin tone, preparing meals, doing house chores at home. Therefore, it can be argued Bangladeshi advertisements prefer to represent the social role of women rather than independent individuals.

\section{b. Stereotypical image of women in advertisements}

While advertising the household products, women are given roles to execute traditional household chores that openly manifest socially constructed gender norms, values and roles. Following the traditional mindset, the Bangladeshi television commercials maintain the representation of women as the other. Some of the characteristics attached to women that only allow the audience to understand female personals as submissive, naive, beautiful objects, good mothers, excellent cooks, perfect housewives. This certainly constructs a traditional women image by deliberate negligence of freedom and potential of a woman as a human being. By portraying gender roles, television advertisements perpetuate the ideology of patriarchal society.

\section{c. Treatment of female models in advertisements}

Moreover, the results found that $60.8 \%$ of the selected ads have used 
female voice overs whereas male voice overs are heard $39.2 \%$. This signifies that female voices are deployed to persuade the audience to buy products. Furthermore, women are more likely to appear as central characters than men in Bangladeshi television commercials. On the contrary, most advertisements portray women as product users rather than product introducers in terms of product authority. The traditional women characters are demonstrated to do domestic works within a home setting and shown as less active than male characters. In some instances, women are shown to depend on men just to purchase a commodity. This implies women are not rational and they are bound to rely on men as in the traditional society system men are endorsed with rational characteristics.

\section{d. Ideology of colorism in advertisements}

Colorism is a common phenomenon in the realm of beauty product consumption where being darker is considered as a disgraceful feeling. The ideology of colorism is cunningly imposed on women that constructs prejudice based on skin tone. In this context, white skin color is perceived as an asset; on the contrary, darker skin tone is merely unwanted. But fairness or imaginary beauty can be attained by being a consumer of the beauty product. This sort of advertisements claim that a woman should have light skin color that elevates to a beautiful, stylish and glamorous look. They endorse an idea that a woman has to achieve fair skin tone and purchase of a fairness product is the only solution. The beauty product commercials play a significant role to make women feel insecure or worry about their skin tone. Such messages highlight women based on their physical beauty; thus ignoring their intellectual ability as a human being.

\section{e. Application of the theory}

Following Hall's (1997) representation theory; firstly, advertisers have fixed and oversimplified the image of women, as a result their potentials are reduced for representation. Secondly, a few characteristics are applied for the representation of women as if their deliberate construction of a female character or gender role is natural. Thirdly, apart from promoting colorism such representations construct stereotypic images of women that hold up the dominant ideology of patriarchy. Fourthly, the mass audiences interpret media text's meanings in a way that they are incapable of using their brain intelligently. Lastly, traditional gender norms prevail in society, but again media continuously manifest and reinforce stereotypes through the process of representation. 


\section{CONCLUSION}

This paper has highlighted how advertisements sustain stereotypical gender norms, value and concept of colorism in terms of socio-political context of Bangladesh. Stereotypical attitudes about the women's roles hold up hegemonic ideology of patriarchal norms; significantly contribute to unequal treatment of women in television commercials. To summarize, key findings of the quantitative analysis follow as the role of beauty conscious, mother and housewife are featured frequently in television commercials of Bangladesh. Interestingly, female voice overs are used more than male voice overs in terms of product authority. The main findings of the qualitative analysis entail the practice of stereotypical gender roles are all evident, but a few advertisements attempt to represent women as career centered or independent individuals. Moreover, the ideology of colorism is clearly apparent in the message of Bangladeshi television commercials that convey to mass audiences. The world of beauty consumption persuades the audience to purchase beauty-enhancing products that in turn allures the consumers to visualize their own outlook lacking perfection.

Over the last decades, there have been quite remarkable changes taking place in women's participation at the economic activities in Bangladesh (Chaity, 2018). The representation of women in television commercials have evolved over a span of time, nevertheless such portrayal still confines women within the traditional notions of gender norms. Thus, it is evident that slight shifts have occurred, these positive changes are at the nascent state. But this should be addressed with importance since the level of change in representing women in advertisements is still quite disappointing.

\section{REFERENCES}

Asemah, E.S., Edegoh, L., \& Ojih, E. (2013). Audience perception of the portrayal of women in television advertising. AFRREV LALIGENS: An International Journal of Language, Literature and Gender Studies, 2, 21-37. https://doi.org/10.4314/LALIGENS.V2I1

Chaity, A. J. (2018, July 12). Women empowerment: Bangladesh sets example for the world. Dhaka Tribune. https://www.dhakatribune.com/opinion/ special/2018/07/12/women-empowerment-bangladesh-sets-example-forthe-world

Grant, S. C. (2020, November 20). What Is Colorism?. Verywellmind. https:// www.verywellmind.com/what-is-colorism-5077380 
Gulati, M. (2014). Analysis of projection of women in advertisements on society. Global Journal of Commerce $\mathcal{E}$ Management Perspective, 3(5), 78-81. https://www.longdom.org/articles/analysis-of-projection-of-women-inadvertisements-on-society.pdf

Gupta, M. (2021). A study on impact of fairness-based advertisements on consumers and consumer perspective on advertisement ban. Psychology and Education Journal, 58(2), 3617-3626. https://doi.org/10.17762/pae. v58i2.2622

Hall, S. (Ed.). (1997). Representation: Cultural representations and signifying practices. Sage Publications.

Hamid, M. K. (2019, May 27). How is Bangladesh faring in gender equality?. The Daily Star. https://www.thedailystar.net/opinion/perspective/news/ how-bangladesh-faring-gender-equality-1749268

Haque, S. F. (2019, October 27). A man's share in 'women's work'. The Daily Star. https://www.thedailystar.net/opinion/society/news/mans-sharewomens-work-1819033

Holtzhausen T. \& Jordaan Y. \& Norths J.E. (2011). The portrayal of women in South African television commercials, Southern African Business Review, 15(3), 167-183. http://hdl.handle.net/2263/18009

Huang, Y., \& Lowry, D. T. (2012). An analysis of nudity in Chinese magazine advertising: Examining gender, racial and brand differences. Sex Roles, 66(7), 440-452. https://doi.org/10.1007/S11199-011-0101-7

Islam, M. M. (2018). Television viewing patterns and program choices of rural and urban audiences, Society $\mathscr{E}$ Change, XII (2), 7-22. http:// societyandchange.com/uploads/1547121143.pdf

Jui, M. U. (2019, August 23). Advertisements of Bangladesh. THE BUSINESS STANDARD. https://www.tbsnews.net/bangladesh/advertisementsbangladesh

Khan, H. (2019, April 1). SuperMom Baby Diaper $\$ No Compromise in Upbringing Baby】 [Video]. YouTube. https://www.youtube.com/watch?v=sQnMTFHddBY

Khan, R. A. (2019). Gender representation in the print media advertisement in Bangladesh [Master's Thesis, Daffodil International University]. http:// dspace.daffodilvarsity.edu.bd:8080/handle/123456789/4830

Kohinoor Chemical Company Bangladesh Limited. (2019, May 29). Fast Wash Detergent Powder [Video]. YouTube. https://www.youtube.com/watch?v=- 
WBOtZL1H2k

Krawczyk, R., \& Thompson, J. K. (2015). The effects of advertisements that sexually objectify women on state body dissatisfaction and judgments of women: The moderating roles of gender and internalization. Body Image, 15, 109-119. https://doi.org/10.1016/j.bodyim.2015.08.001

Kumar, S. (2017). Representation of women in advertisements. International Journal of Advanced Scientific Technologies in Engineering and Management Sciences, 3(1), 26-28. http://dx.doi.org/10.22413/ijastems/2017/v3/ i1 $/ 41314$

Lux Bangladesh. (2019, June 4). LUX Beauty Is Our Right [Video]. YouTube. https://www.youtube.com/watch?v=R7Fsa-uXIc8

McLeod, S. (2019). What's the difference between qualitative and quantitative research? SimplyPsychology. https://www.simplypsychology.org/qualitativequantitative.html?fbclid=IwAR1sEgicSwOXhmPHnetVOmtF4K8rBRM yDL-TMPKYUjsuxbJEe9MVPymEdg

Nagi, P. (2014). Projection of women in advertisement: A gender perception study. International Journal of Managerial Studies and Research, 2 (9), 75-88. https://www.arcjournals.org/pdfs/ijmsr/v2-i9/9.pdf

Nahar, K. K. (2019). Role portrayals of women in Bangladeshi television advertisements and it's changes with the context of time. International Journal of Scientific $\mathcal{E}$ Engineering Research, 10(7), 1-11. https://ssrn.com/ abstract $=3732259$

Pia, T. T. (2018, June 20). WOMEN IN ADVERTISEMENT: HOW WE ARE SHOWING THEM AND WHAT CAN BE CHANGED. BBF DIGITAL: Inspiring the Nation. https://bbf.digital/women-in-advertisement-how-weare-showing-them-and-what-can-be-changed

Pureit Bangladesh. (2019, Jan 14). Pureit Classic|Safer Than Boiled Water [Video]. YouTube. https://www.youtube.com/watch?v=W8HNsU9fnqM

Radhuni Bangladesh. (2019, July 18). Radhuni Basic Spice - Amar Radhuni Ami Jani- 50 Sec. [Video]. YouTube. https://www.youtube.com/ watch? $=\mathrm{XMmLwWiH1nk}$

Rosul, S. (2011). A critical discourse analysis of fairness-product advertisements for women and men [Master's Thesis, East West University]. http://dspace. ewubd.edu:8080/handle/123456789/128

Vaseline Bangladesh. (2020, September 13) Vaseline Healthy White | ভসেলনি 
Informasi, Vol. 51. No. 2. (2021), 249-266

হলেথণ হৃইইট | [Video]. Youtube. https://www.youtube.com/ watch?v=ce-IIWxesvk

Witswon. (2019, August 27). Fair and lovely fairness cream advanced multivitamin $80 \mathrm{~g}$ in Bangladesh [Video]. YouTube. https://www.youtube.com/ watch? = $^{\circ}$ fGMwjZJ4ng 